\title{
VARIAÇÃO E MUDANÇA LINGUÍSTICA: AS INFLUÊNCIAS HISTÓRICO-SOCIAIS NO ESPAÇO GEOGRÁFICO
}

\author{
Antônia Samara Souza do NASCIMENTO' \\ Tamara Cristina Penha da COSTA2 \\ Robervania de Lima Sá SILVA
}

\begin{abstract}
RESUMO
O presente artigo faz parte de um trabalho de conclusão de curso, para tanto, a pesquisa ainda se encontra em andamento, mas a partir de alguns levantamentos obtivemos alguns resultados bibliográficos. Objetivo do mesmo consiste em realizar uma análise comparativa em relação a algumas palavras utilizadas por pessoas idosas com faixa etária a partir de 60 anos, residentes no bairro Capelinha e Morada do Sol pertencentes ao município de Conceição do Araguaia-PA, bem como verificar quais fatores externos (metaplasmos) são responsáveis por este processo de mudança. A pesquisa compreende à um estudo exploratório de cunho qualitativo por meio de uma entrevista estruturada a partir de gravações, tendo como base um questionário com perguntas abertas e fechadas. Diante dos primeiros resultados, conclui-se que, a língua é múltipla, heterogênea, variável e mutável. A língua portuguesa, assim como todas as outras, passa por um processo de mudança, resultado da ação humana na sociedade, que repercuti na evolução das palavras, fenômeno que se faz presente desde a história da formação da língua portuguesa. Apesar da evolução das palavras muitas permanecem conservadas, sendo utilizadas por grande parte das pessoas juntamente com sua nova forma, com isso as pessoas que as usam passam a ser mal vistas na sociedade. Dentre os teóricos utilizados para esta pesquisa destaca-se: Bagno (2003, 2004, 2006 e 2007), Bortoni-Ricardo (2010), Faraco (2008), Matos e Silva (2004), Molica e Braga (2004), Mussalin e Bentes (2008), Saussure (2002), na área de metodologia cientifica foram estudados: Gil (2008) e Marconi e Lakatos (2007).
\end{abstract}

Palavras-chave: Mudança. Variação. Arcaísmo linguístico.

\begin{abstract}
The present article is part of a work of conclusion of course, for that, the research still is in progress, but from some surveys we obtained some bibliographical results. The aim of this study is to perform a comparative analysis of some words used by elderly people aged 60 and over, living in the neighborhood capelinha and address of the sun belonging to the municipality of Conceição do Araguaia-PA, as well as verify which external factors (metaplasms) are responsible for this process of change. The research comprises an exploratory study of qualitative nature through a structured interview based on recordings, based on a questionnaire with open and closed questions. In view of the first results, it is concluded that the language is multiple, heterogeneous, variable and changeable. The Portuguese language, like all the others, goes through a process of change, a result of human action in society, which has repercussions on the evolution of words, a phenomenon that has been present since the history of the formation of the Portuguese language. In spite of the evolution of the words many are conserved, being used by a great part of the people along with its new form, with that the people that use them are poorly seen in the society. Among the theorists used for this research are: Bagno (2003, 2004, 2006 and 2007), Bortoni-Ricardo (2010), Faraco (2008), Matos e Silva (2004), Molica e Braga (2004), Mussalin e Bentes (2008), Saussure (2002), in the area of scientific methodology were studied: Gil (2008) and Marconi and Lakatos (2007).
\end{abstract}

Keywords: Change. Variation. Linguistic Archeology.

\footnotetext{
1 Universidade do Estado do 3 Doutoranda em Ensino de Pará (UEPA). E-mail: antonia- Língua e Literatura na UFT. samarasousa@gmail.com

2 Universidade do Estado do Pará (UEPA). E-mail: tamaracristina390@gmail.com

Foi professora substituta da Universidade do Estado do Pará E-mail: robervania. sa@bol.com.br. E-mail: robervania.sa@bol.com.br
}

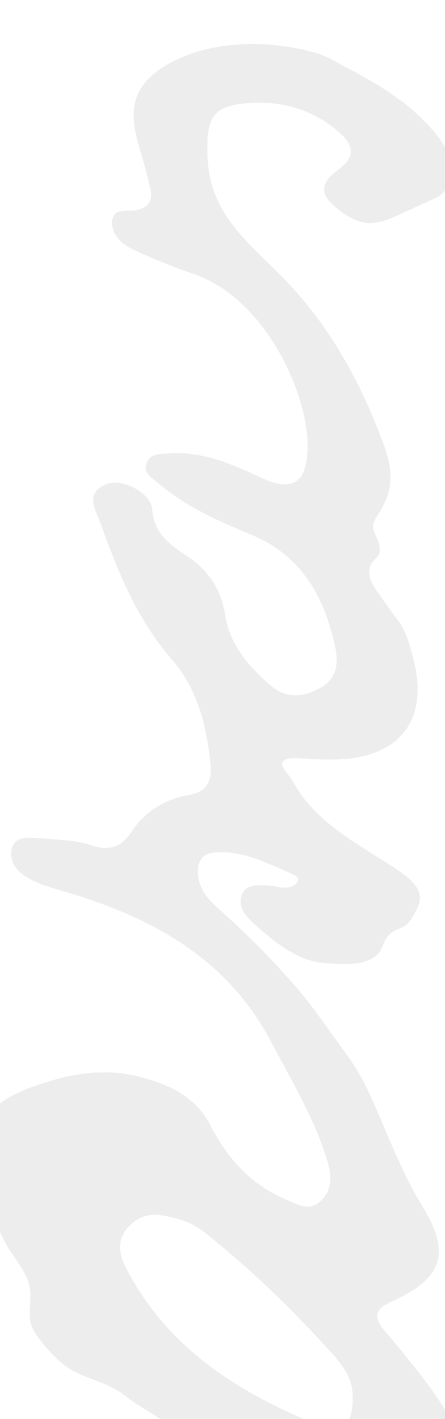




\section{INTRODUÇ̃̃O}

A linguagem humana está a todo momento sujeita a diversas modificações, isto é, a presença de fatores externos como meio social e internos, interferem na estrutura das palavras, que por sua vez são afetadas, fazendo com que elas evoluam. Foi assim que sempre aconteceu, pois os seres humanos estão em constante evolução social e linguística, sendo assim, os vocábulos se desenvolvem juntamente com os indivíduos em sociedade.

A língua está em constante mudança no espaço, sofrendo variações em diferentes lugares, pois a sociedade evolui e com ela não poderia ser diferente, pois precisa acompanhar as tendências de cada período, uma vez que são os próprios sujeitos responsáveis pelas transformações que ocorrem na língua adequando-a de acordo com seus interesses. Com isso as palavras não apenas geram outras, mas também passam a ganhar novos significados.

Mesmo com a evolução das palavras é possível observar que ainda existem formas antigas que são utilizadas na língua, formas que se encontram em desuso, mas que permanecem gerando um conflito com as outras, na qual muitas pessoas dizem que são erradas pelo fato de não adquirirem conhecimento de que elas um dia existiram e fizeram parte da norma padrão, mais precisamente podemos dizer que $o$ "errado" de hoje foi correto de "ontem".

Ressalta-se que elas permanecem conservadas principalmente por parte de pessoas idosas, na qual em épocas anteriores faziam parte de seu contexto social, é importante lembrar que além das pessoas idosas, existem aqueles que residem em zonas rurais que também apresentam estes traços, o interessante é que elas são responsáveis por manter a forma mais original das palavras, uma vez que sofrem menos modificações por residirem em locais mais distantes.

Sendo assim, por meio do conhecimento sobre a história de uma palavra e seu processo de formação os indivíduos irão refletir significativamente na mudança de sua mentalidade fazendo uma distinção do que é "antigo" e "errado", fato que muitos consideram sinônimos levando ao preconceito por falta de informação a respeito do assunto.

\section{ARCAISMO LINGUÍSTICO}

A linguagem assim como um organismo natural está em constante evolução, isto é, comparável à uma planta, que nasce, cresce, envelhece e morre. Shleicher apud Mussalim e Bentes (2008), o que resulta em mudança na estrutura, no sentido, bem como no surgimento, no desuso e na conservação de algumas palavras, assim como o desuso de algumas, além da conservação de outras. Em relação ao último aspecto, é preciso ressaltar que essas transformações não implicam na eliminação das palavras já existentes. Ao contrário, enquanto boa parte das pessoas as mantêm conservadas em sua fala, outras incorporam a forma em uso corrente.

Disso resultará o natural conflito entre a palavra "evoluída" e a que se tornara arcaica. A questão é que esse processo nem sempre é compreendido e/ou aceito pela perspectiva normativista de estudo da língua(gem), resultando, via de regra, em preconceito linguístico, pois grande parte das pessoas as mantêm conservadas em sua fala, quanto outras incorporam sua forma atual, assim, ocorre um conflito entre a palavra evoluída e palavra que se tornou arcaica, mais precisamente o preconceito linguístico.

$\mathrm{O}$ arcaísmo linguístico consiste no uso de palavras ou expressões antigas, ou seja, palavras que em épocas anteriores faziam parte do léxico de uma comunidade linguística. Essas, em decorrência do surgimento de novas palavras entraram em desuso.

Convém ressaltar que, as palavras arcaicas mantêm conservadas em sua estrutura aspectos fonéticos, morfológicos, sintáticos e lexicais. 
as quais, futuramente também se tornarão arcaicas pelo natural processo de evolução da língua, como dissemos acima. Afinal, a língua está sempre evoluindo, [...] não há como impedir o desaparecimento de formas linguísticas antigas e sua substituição por novas maneiras de falar [...]". As palavras, então, passam a se adequar a uma nova comunidade linguística. (BAGNO, 2003, p. 108).

\section{COMPREENDENDO A NOÇÃO DE ERRO NA LÍNGUA FALADA}

As palavras que compõem a língua portuguesa apresentam um importante contexto histórico-social, capaz de demostrar o processo de mudança que sofreram ao longo dos anos, bem como explicar o motivo pelo qual a maioria das pessoas usam palavras que são tidas como erradas pelos estudos gramaticais tradicionais, as formas variantes não-padrão da língua. Por isso é preciso compreender que "[...] As línguas mudam incessantemente, e a definição do "certo", do "agradável" e do "adequado" também. [...]”, (MUSSALIN e BENTES, 2008, p. 40).

Infelizmente, a deficiência ou a ausência de conhecimentos sobre a formação e o processo de evolução da língua portuguesa leva muitas pessoas a formularem ideias vazias e desprovidas de sentido quanto àquilo que desconhecem. A partir, então, de noções pré-concebidas, surge o preconceito linguístico. Este, segundo Bortoni-Ricardo (2010), via de regra, advém de pessoas de classe social elevada, e fundamenta-se, tão somente, nas avaliações socioculturais negativas que estes indivíduos fazem do modo de falar das demais classes sociais.

Para melhor compreensão, esta mesma autora destaca que o tempo é um fator que influencia e promove mudanças na língua. Nesse sentido, para os sociolinguistas não existem erros na língua falada, mas sim diferentes formas de se dizer a mesma coisa. $\mathrm{O}$ erro somente ocorre, segundo ela, se um único indivíduo emite fonemas de modo particularizado e destoante dos demais membros de sua comunidade linguística. Vejamos:

Do ponto de vista linguístico, o erro não existe, o que existe são formas diferentes de usar os recursos potencialmente presentes na própria língua: se milhões de brasileiros dizem trabaio- $e$ não "trabaco", "trabavo", "trabazo" etc. - é porque a transformação de "lh" em " $i$ ” é uma virtualidade prevista na própria arquitetura fonológica da língua portuguesa. Só poderia falar em "erro" se cada cidadão errasse, individualmente e de modo particular, no momento de produzir aquele fonema. (BARTONI-RICARDO, 2010, p. 08)

Conforme podemos observar no excerto acima, não existe erro não na língua, o que existe é um "profundo e estranho preconceito social. [...]", que por sua vez parte de pessoas de classe social elevada para com aqueles de classe social menos privilegiada, conforme dito anteriormente (BAGNO, 2004, p. 16).

O conceito de "erro", desse modo, está relacionado com o nível social em que o falante está inserido, uma vez que quanto mais baixo estiver na pirâmide das classes sociais, mais erros serão detectados em sua fala por parte dos falantes privilegiados. Nesse sentido, os erros variam de acordo com quem usa e contra quem são usados. Os grupos dominantes passam a classificar as expressões como erros de acordo com seus interesses e ideologia, não aceitando as variedades estigmatizadas $^{4}$ dos falantes tidos como incultos ${ }^{5}$. Vale ressaltar ainda que os "erros" são menos perceptíveis na fala de pessoas que pertencem à mesma classe social, no caso dos falantes letrados (BAGNO, 2004).

As formas linguísticas usadas pelos falantes das camadas sociais menos privilegiadas, sejam elas na fala ou na escrita, quando incorporadas pelos falantes cultos $^{6}$ aos poucos passam a ser vistas como corretas (BAGNO, 2004).

Vale ressaltar, que a mudança linguística não se dá apenas em virtude de um
4 Variedades estigmatizadas: [...] variedades linguísticas que caracterizam os grupos sociais desprestigiados do Brasil [...]. (BAGNO, 2003, p. 67).

5 Inculto: "Que ou quem não tem cultura, não tem preparo intelectual, não tem erudição" (HOUAISS, 2009).

6 Falante culto: "[...] indivíduo com grau de escolaridade superior completa, nascido e criado em zona urbana." (BAGNO, 2004, p. 39). 
único falante, ou seja, um único indivíduo não pode mudar nem modificar a estrutura da língua, ela somente ocorre quando incorporada por grande parte dos falantes, com isso, no decorrer do tempo as transformações também ocorrem na escrita, passando a ser incorporadas pelas as gramáticas. (SAUSSURE, 2002).

A desvalorização, a rejeição e o preconceito contra as variedades linguística implicam em outro problema: a negação de sua própria língua, já que esta é constituída em grande parte por variações vindas de quase todos os falantes brasileiros. Assim, “[...] os brasileiros urbanos letrados não só discriminam o modo de falar de seus compatriotas analfabetos, semianalfabetos, pobres, excluídos, como também discriminam o seu próprio modo de falar, as suas próprias variedades linguísticas. [..."”, (BAGNO, 2004, p. 75).

Diante disso, não há, para nós, outra alternativa senão o reconhecimento de que as variantes não-padrão são formas linguísticas alternativas, legítimas, diferentes e dinâmicas de usar os recursos constantes na própria arquitetura fonológica de nossa língua.

Conforme Bortoni-Ricardo (2010), a variação linguística ocorre em todos os setores da sociedade, escola, igreja etc., sendo mais evidente no ambiente familiar, haja vista este ser o lugar onde ocorre mais liberdade de expressão entre os membros. O problema surge, quando esta liberdade de falar em família, na maioria das vezes, é levada para o ambiente escolar.

O que precisa ficar claro, afinal, é que toda variedade linguística, juntamente com suas variantes, atendem às necessidades da comunidade de seres humanos que a empregam. Quando deixarem de atender, elas inevitavelmente sofrerão transformações para se adequarem às novas necessidades.

\section{COMO AS PALAVRAS SE MANTÊM CONSERVADAS?}

O léxico que compõe a língua portuguesa é dinâmico, maleável e flexível, em virtude da comunidade de falantes que colabora para o dinamismo ou conservação das palavras.

Outrossim, as escolhas das palavras, mesmo que ocorram de forma aleatória e inconsciente, ajudam a entender o contexto ao qual os falantes pertencem e revelam particularidades relacionadas ao aspecto social, econômico, nível de escolaridade, entre outros.

Em determinados lugares, onde muitas pessoas utilizam palavras antigas, e que não são mais empregadas pela maioria dos membros daquelas comunidades linguísticas, fala-se que ocorre "vício de linguagem". Outra expressão bastante usada é arcaísmo linguístico, isto é, palavras ou expressões antigas que caíram em desuso, conforme pontuamos no início. Essas palavras são bastante utilizadas por pessoas que residem nas zonas rurais que, por sua vez, as mantêm conservadas.

Em se tratando de linguagem, esse fenômeno é totalmente previsível, lógico e coerente, tendo em vista que a conservação/manutenção de determinadas formas linguísticas apresenta estreita relação com a política de colonização local. Logo, "quanto mais antiga a colonização de um lugar, mais traços arcaicos sobrevivem na sua língua” (BAGNO, 2006, p. 146).

Seguindo o raciocínio do autor citado, então, podemos afirmar que as pa-

7 "entonce" ("então"), do latim: in tunce.

8 “despois" (“depois”), do Latim, después. lavras "entonce" e "despois", formas bastante presentes na fala de pessoas que residem nas zonas rurais, estão mais próximas do latim, do que as palavras que fazem parte da norma-padrão utilizada nas grandes cidades/regiões. Aquelas, por assim dizer, são "responsáveis" por manter a forma mais original das palavras.

Fatores como as dificuldades de acesso aos meios de transporte e comunicação podem contribuir para o isolamento das pessoas em suas localidades, fazendo com que mantenham pouco contato com a influências dos centros urbanos e, por conseguinte, a conservação da fala dos "caipiras". Estes, por sua vez, apresentam maior mudanças nas palavras, pois vivem em uma sociedade que está em constante transformação (cf. BORTONI-RICARDO, 2010). 
Para além desses aspectos, deve-se dar atenção aos diversos mitos e preconceitos oriundos de abordagens ideológicas excludentes que, de um lado, fundamentados apenas em seu prestígio político e econômico, instituem seus falares como superiores, mais bonitos e corretos, enquanto, de outro, tentam desqualificar as variedades ou falares regionais, legítimos instrumentos indenitários de determinados grupos sociais (BORTONI-RICARDO, 2010).

Aprofundando um pouco mais, a mesma autora ressalta que "a flutuação entre /1/ e /r/ pós-vocálico é própria das comunidades situadas no polo rural, onde também podemos ouvir galfo/garfo; calvão/carvão. (Idem, p.56).

Isso posto, entendemos que a conscientização dos alunos quanto às diferenças entre as variedades linguísticas é uma das ações fundamentais a serem desenvolvidas, a fim de tentar amenizar este problema.

Como forma de amenizar este problema que cada vez mais se faz presente na sociedade é preciso conscientizar o aluno quanto às diferenças, para que ele possa começar a monitorar seu próprio estilo, mas esta conscientização precisa ocorrer sem prejuízo para o processo de ensino/aprendizagem da língua, isto é, sem causar interrupções inoportunas. (Idem, p. 42).

Bortoni Ricardo (2010), destaca que a palavra "INTÉ- é uma forma arcaica da preposição até", a mesma consiste em um arcaísmo que permaneceu conservado no polo rural e praticamente desapareceu dos falares urbanos. Ainda ressalta que "muitas formas encontradas hoje no polo rural são arcaísmos que se preservaram, alguns exemplos podem ser encontrados em obras literárias como, Os Lusíadas, poema que foi escrito pelo português Luís Vaz de Camões [...”".

\section{MUDANÇA LINGUÍSTICA E VARIAÇÃO DIATÓPICA}

A modificação que ocorre na língua ${ }^{9}$ está relacionada com sua utilização por parte dos falantes em virtude do processo de interação social, isto é, fatores internos, que de forma inconsciente, vão alterando "as regras de funcionamento da língua", e, dessa forma, adequando-a a suas necessidades de processamento mental, de comunicação e interação. Assim, a língua sofre modificação por conta dos falantes, não existindo sem os mesmos. Destaca-se também a presença de fatores externos, ou seja, histórico-sociais. (BAGNO, 2007).

O processo de mudança ocorre de forma natural e demorada, atingindo os aspectos lexicais, fonológicos, fonéticos, semânticos, sintáticos e morfológicos da língua. Desse modo, vale ressaltar, que a mudança sempre esteve presente na história da formação das línguas, o Português por exemplo originou-se a partir do latim vulgar.

Todos sabemos que as línguas mudam com o tempo. Basta compararmos o português com o latim, ou até com o próprio português da época medieval, para notarmos diferenças em todos os níveis, desde a semântica até a sintaxe, passando pela fonologia, pelo léxico, pela morfologia, etc. Esta mudança a longo prazo, através dos séculos, não se processa de maneira instantânea ou abrupta, como se numa determinada manhã a população inteira acordasse falando de maneira diferente da do dia anterior. De fato, as mudanças linguísticas normalmente se processam de maneira gradual em várias dimensões. (MOLICA, 2004, p.43)

Todo esse procedimento que envolve a mudança tem como objetivo primordial manter a língua sempre em funcionamento, visto que a mudança linguística ocorre conforme seus usuários a utilizam, inferindo, dessa forma novos sentidos e até a adoção de novos padrões transformando-a. Seja qual for o contexto que envolva essa mudança, a mesma tona-se relevante para o funcionamento da língua e adaptação dos seus usuários, na qual alguns tendem a manter traços conservados, e outros a adotar novos traços, resultando em muitos casos em sua competição, com isso, per- VOL. 14 | N.2 | DEZ. 2017
9 [...] a língua na concepção dos sociolinguistas, é intrinsecamente heterogênea, múltipla, variável, instável e está sempre em desconstrução e em construção. [..] a língua é um processo, um fazer-se permanente e nunca concluído. A língua é uma atividade social, um trabalho coletivo, empreendido por todos os seus falantes, cada vez que eles se põem a interagir por meio da fala ou da escrita. (BAGNO, 2007, p. 36). 
cebe-se que a mudança não ocorre de forma homogênea dentro de uma comunidade de falantes. (BAGNO, 2007).

As alterações/variações linguísticas ocorrem a partir do momento em que a língua passa a ser utilizada de maneira diferente daquela apresentada como única e oficial. Sendo o sistema linguístico ativo passa, então, por adaptações que os próprios falantes fazem, criando alternativas de acordo com as suas necessidades comunicativas conforme dito anteriormente.

Com base na ideia acima, entende-se que o monolinguísmo, defendido por alguns, consiste em um mito, pois a variação linguística constitui a língua nacional, sendo observada em todos os âmbitos (cf. MATTOS E SILVA, 2004; FARACO, 2008). A grande questão está justamente na incompreensão da temática, pois, normalmente, os sujeitos que apresentam variações em suas falas são alvo de preconceito linguístico e exclusão social.

As aptidões desenvolvidas pelos falantes de uma mesma língua assinalam fortemente para a maneira como o indivíduo se posiciona socialmente, sendo o seu [da língua] uso revelador de aspectos tanto geográficos como sociais.

De acordo com Mussalin \& Bentes (2008, p. 34), “[...] de uma perspectiva geral, podemos descrever as variedades linguísticas a partir de dois parâmetros básicos: a variação geográfica (ou diatópica) e a variação social (ou diastrática) ". Vejamos:

A variação geográfica ou diatópica está relacionada às diferenças linguísticas distribuídas no espaço físico, observáveis entre falantes de origens geográficas distintas [...]. [...] A variação social ou diastrática, por sua vez, relaciona-se a um conjunto de fatores e que têm a ver com a identidade dos falantes e também com a organização sociocultural da comunidade de fala, [...]. (MUSSALIN \& BENTES, 2008, p. 34-35).

Percebe-se assim que a complexidade que envolve as formas linguísticas acentua-se especialmente no momento de interação social. Logo, definir e/ou aceitar que a língua apresenta variações em relação à apresentada como oficial e, sobretudo, conhecê-las, torna-se relevante para a compreensão da própria história nacional.

As transformações da língua, isto é, o processo de variação linguística, resulta no desaparecimento ou surgimento de novas palavras, bem como de sua significação, estas por sua vez, após longo período de tempo, são diretamente incorporadas à gramatica normativa.

Considera-se a própria sociedade, com seus diferentes grupos e culturas, como decisiva para essas mudanças. Logo, tendo em vista que as pessoas possuem hábitos linguísticos e diferentes níveis de escolarização, a forma de comunicação ocorrerá de diferentes maneiras, refletindo assim na língua escrita e na oral.

Todavia, e apesar de todos os esforços dos estudiosos da linguagem, ainda existem preconceitos e estigmas que envolvem essas variações, fazendo com que as mesmas sejam, por vezes, consideradas erradas, inconvenientes, sem prestígio e, consequentemente, aconselhadas serem evitadas.

Quando se fala em variação é preciso compreender que ela está ligada a vários fatores, como o meio social, a escola, igreja e principalmente à família, pois é o lugar em que ocorre mais liberdade de expressão entre os membros. O problema, na maioria das vezes, surge quando esta liberdade de falar em família é levada para o ambiente escolar, sobretudo para a escrita, o que possivelmente resultará n na recusa por parte do professor e o preconceito linguístico-social entre os membros da classe. (BORTONI-RICARDO, 2010).

\section{CONSIDERAÇÕES FINAIS}

Compreender a história e o processo de mudança de uma língua é funda- 
vam esta riqueza vocabular. É preciso entender que a língua por ser um organismo vivo, assim como o homem, está em constante evolução, assim cabe aos falantes adequar-se à ela.

Por meio deste trabalho pretende-se promover uma reflexão crítica mostrando a importância do conhecimento histórico-social das palavras afim de levar o indivíduo a repensar seus conceitos de "errado", pois o que se tem percebido ao longo deste estudo é que alguns vocábulos utilizados por muitas pessoas que são considerados "errados" na verdade não passam de expressões antigas que um dia fizeram parte da norma padrão da nossa língua portuguesa, mas devido o processo de mudança que sofrem ao longo dos tempos outras surgiram fazendo com as demais entrassem em desuso, ou seja se tornaram "arcaicas".

Dessa forma, é importante lembrar que muitas palavras ainda se mantem conservadas por grande parte das pessoas, fazendo com que permaneçam com a forma mais próxima de sua primitiva, isto ocorre principalmente em áreas distantes dos centros urbanos que mantem pouco contato com as transformações que ocorrem na sociedade.

Compreender a história de uma língua é fundamental, uma vez que cada uma delas apresenta uma explicação para tais eventualidades e são desconhecidas por parte de algumas pessoas, se pararmos para analisar a forma que uma pessoa utiliza uma palavra hoje para sua forma original iremos perceber o quanto ela mudou ou até mesmo se observarmos textos literários de diferentes épocas, uma vez que estes apresentam uma riqueza de vocábulos antigos, isto devido os fatores histórico-sociais que estão sempre atuando na língua, fazendo com que evolua juntamente com o homem e a sociedade.

\section{REFERÊNCIAS}

BAGNO, Marcos. A norma oculta: Língua e poder na sociedade brasileira. Parábola. São Paulo: Parábola Editorial, 2003.

. Português ou Brasileiro? Um convite à pesquisa. $4^{\circ}$ ed. São Paulo: Parábola Editorial, 2004.

. A língua de Eulália: Novela sociolingüística. São Paulo: Contexto, 2006.

. Nada na língua é por acaso: por uma pedagogia da variação linguística. São Paulo: Parábola editorial, 2007.

FARACO, Carlos Alberto. Norma culta brasileira: desatando alguns nós. Parábola editorial: São Paulo, 2008.

GIL, Antonio Carlos. Como elaborar um projeto de pesquisa. 4 ed. São Paulo: Atlas, 2008.

MARCONI, M. A.; LAKATOS, E. M. Fundamentos de metodologia cientifica. São Paulo: Atlas, 2007.

MATTOS E SILVA, Rosa Virgínia. O português são dois: novas fronteiras, velhos problemas. - São Paulo: Parábola Editorial, 2004.

MOLICA, C; BRAGA, N, L. Introdução à sociolinguística: o tratamento da variação. 2 ed. São Paulo: Contexto, 2004.

MUSSALIN, F; BENTES, A, C (org.). Introdução à linguística: domínios e fronteiras. 8. Ed. São Paulo: Cortez, 2008.

RICARDO, Bortoni. Educação em língua materna: a sociolinguística na sala de aula. São Paulo: Editorial, 2010.

SAUSSURE, Ferdinand d. Curso de Linguística Geral. $24^{\circ}$ ed. São Paulo: Pensamento-Cutrix, 2002. 